\title{
Política pública de esporte e lazer: uma análise bibliométrica a partir da base Scopus
}

\author{
Sport and Leisure Public Policy: A Bibliometric Analysis from the \\ Scopus Database
}

Resumo: A pesquisa bibliométrica é uma técnica estatística que contribui para o desenvolvimento das ciências a partir da mensuração de dados de produção acadêmica de uma determinada área do conhecimento. 0 objetivo deste artigo é apresentar indicadores bibliométricos relacionados ao tema política pública de esporte e lazer, usando como referência a base Scopus, em que se buscaram informações sobre o tema estudado no Brasil e no mundo entre 2008 e 2017. Partindo de uma pesquisa quantitativa e de cunho exploratório, verificou-se que o tema política pública de esporte e lazer, em termos de publicações no mundo, cresceu 14\%, enquanto, no Brasil, 0 crescimento foi de $33,6 \%$. A instituição que mais publica sobre o tema no mundo é brasileira, e o autor com o maior número de publicações no mundo também é brasileiro. 0 periódico que mais apresenta publicações sobre o tema no mundo é a revista Movimento do Brasil.

Palavras-chave: Bibliometria. Política Pública. Esporte. Lazer
Abstract: Bibliometric research is a statistical technique that contributes to the development of science by measuring data on academic production in a given area of knowledge. This paper aims at presenting bibliometric indexes related to the theme Sports and Leisure Public Policies, using as reference the Scopus database, in which information on the theme was sought in Brazil and worldwide between 2008 and 2017. From a quantitative research of exploratory approach, it was verified the theme Sports and Leisure Public Policies concerning publications all over the world increased 14\%, while, in Brazil, the growth was of $33.6 \%$. The institution that publishes most on this subject in the world is a Brazilian one, and the author with the largest number of publications is from Brazil as well. The journal with the most publications on the theme worldwide is the journal Movimento do Brasil.

Keywords: Bibliometrics. Public Policy. Sports. Leisure.

\section{Mario Mecenas Pagani}

Mestre em Educação Física, doutorando em Planejamento Regional e Gestão da Cidade - UCAM-

Campos-RJ, docente do Instituto Federal Fluminense - Campus Bom Jesus do Itabapoana - mario. pagani@iff.edu.br - (22) 98115-6314

\section{Eduardo Shimoda}

Doutor em Produção Animal, docente do Programa de Doutorado em Planejamento Regional e Gestão da Cidade - UCAM-Campos-RJ - shimoda@ucam-campos.br

\section{Ludmila Gonçalves da Matta}

Doutora em Sociologia Política, docente do Programa de Doutorado em Planejamento Regional e Gestão da Cidade - UCAM-Campos-RJ - ludmatta@yahoo.com.br

\section{Endereço para correspondência:}

Rua Gumercindo de Freitas, 79, apartamento 903, bloco 1, bairro Parque São Caetano -

Campos dos Goytacazes (RJ), CEP 28030-295. 


\section{Introdução}

Uma eficiente forma de mensurar e diagnosticar os esforços de pesquisa e publicação relacionados a um determinado tema é a bibliometria. Este ramo da ciencitometria pode contribuir fornecendo dados estatísticos a respeito da evolução temporal, concentração geográfica de esforços, áreas que mais têm investido, entre outras informações interessantes.

A maioria dos estudos que abordaram o tema política pública de esporte e lazer foram caracterizados como relatos de experiência (STAREPRAVO, 2007; STAREPRAVO; MEZZADRI, 2007). Ainda segundo os mesmos autores, enquanto cultura corporal do brasileiro, o esporte nunca havia sido evidenciado pelos governantes do País, embora já houvessem surgido no Brasil, em 1893, o basquetebol e, na sequência, os clubes de regatas e, com eles, o desenvolvimento do futebol brasileiro. Sua relevância político-social nunca havia chamado a atenção do governo.

A partir de 1937, com o Estado Novo, a relação entre Estado e esporte ganhou atenção especial. Buscando desenvolver e fortalecer um ideário de nação, o governo começou a centralizar a organização esportiva no País (Linhales, 1996). No transcorrer de mais de 50 anos, esse quadro quase nada mudou. Porém, a situação começou a se modificar com a promulgação da Constituição Federativa do Brasil (CF) (BRASIL, 1988), atribuindo ao Estado o dever de fomentar as práticas esportivas como um "direito de cada um".

A partir dos dados históricos, percebe-se que o Estado e os seus governantes nunca se preocuparam em suas ações com o esporte, não havendo nenhuma atenção social muito menos interesse em desenvolvê-lo enquanto patrimônio da cultura corporal do povo brasileiro. Tampouco cuidaram de usar o esporte e sua prática como suporte para a garantia de direitos básicos, como educação, lazer e saúde. Nota-se uma mudança nessa configuração a contar da CF (BRASIL, 1988), em que o esporte passou a ter um caráter mais social e menos nacionalista, sendo esta uma função do Estado e dos governos (LINHALES, 1996).

Nesse contexto, o objetivo do presente trabalho é apresentar indicadores bibliométricos relacionados ao tema política pública em esporte e lazer, usando como referência a base Scopus.

\section{Política pública de esporte e lazer}

As pesquisas em políticas públicas no Brasil caracterizam-se, na sua maioria, por exposições empíricas, o que dificulta uma acumulação do conhecimento, de acordo com Melo (1999), devido a uma proliferação horizontal de estudos de caso e/ou relatos de experiência.

Vislumbra-se a possibilidade de produção do conhecimento a partir do surgimento da Rede Cedes, conhecimento este voltado para os gestores do esporte e lazer, possibilitando promover a aproximação do subcampo científico/acadêmico ao subcampo político/burocrático (STAREPRAVO, 2018).

Quando da criação da Rede Cenesp, grupos de pesquisa e pesquisadores de esporte e lazer haviam sido escolhidos para participarem da Rede por seu viés nas ciências humanas e sociais. Com o surgimento da Rede Cedes, o Ministério da Educação buscou garantir uma estrutura que pudesse atender às necessidades dos grupos e pesquisadores, pois a concepção da nova Rede era muito similar à da Cenesp (STAREPRAVO et al., 2014).

A partir de entrevistas com gestores esportivos, verificou-se que, apesar do subcampo político/burocrático não estar sendo apropriado pelo conhecimento produzido pelo subcampo cientííco/acadêmico das políticas públicas de esporte e lazer, este parece ser o desejo de diversos gestores (STAREPRAVO et al., 2014).

Tendo em vista essa necessidade dos gestores, percebeu-se um aumento na produção de estudos sobre 0 esporte enquanto fenômeno social. De acordo com Bento (2013), essa expansão deve-se a uma ressignificação do esporte enquanto um fenômeno polissêmico e polimórfico, possibilitando diferentes aplicações de acordo com as necessidades dos grupos que o utilizam, como também sua aplicação em disciplinas acadêmicas variadas.

Outros estudos buscaram identificar algumas políticas públicas de esportes do governo federal. 0 Programa Segundo Tempo (PST) foi um dos temas pesquisados, em que Santos, Starepravo e Souza Neto (2015) analisaram a participação dos municípios da Região Nordeste, que, ao longo de dez anos, não tiveram acesso a esse programa, produzindo um vazio assistencial. Concluíram que, para um programa que se propõe a democratizar o esporte e atender prioritariamente populações vulneráveis, a existência, por si, só, do vazio assistencial depõe 
contra seus objetivos.

Ao olhar o esporte com seus diferentes significados e objetivos utilizando-o como ferramenta que possa desenvolver o indivíduo, os grupos de pessoas e a comunidade, ele vai muito além de uma simples prática esportiva; pode possibilitar a melhoria da qualidade de vida, do bem-estar geral; contribuir para a socialização diminuindo alguns riscos sociais, como a pobreza, a violência, o desemprego; e melhorar a educação (REVERDITO, et al., 2016; MORAES, et al., 2017).

Buscando identificar quais eram as publicações sobre projetos esportivos no Brasil, Caron, Marchi Jr. e Silva (2018) realizaram um estudo de mapeamento da produção científica sobre projetos esportivos no Brasil, objetivando auxiliar na discussão sobre a utilização do esporte em projetos sociais. As buscas foram realizadas no Portal de Periódicos da Capes, no Portal Regional da Biblioteca Virtual em Saúde (BVS) no Scielo. Os resultados foram os seguintes: 29 artigos, 9 dissertações de mestrado e 2 teses de doutorado, datadas entre 2003 e 2016.

Esses autores identificaram que os projetos esportivos não ficam restritos à educação física, sendo a maioria dos projetos vinculados à área, mas também, a projetos nas áreas de educação, medicina e psicologia.

\subsection{Bibliometria}

0 homem sempre esteve à procura de informações e novos conhecimentos. Assim, essa busca constante faz com que as informações sejam disseminadas pelo mundo a partir de novos conhecimentos; por isso pesquisadores fazem o levantamento do inventário das atividades científicas nos mais diversos campos do conhecimento. Hoje, uma ferramenta muito utilizada para medir a produção científıca é a denominada bibliometria (SILVA; SANTOS; RODRIGUES, 2011).

0 uso de métodos estatísticos e matemáticos para mapear informações a partir de registros bibliográficos de documentos (livros, periódicos, artigos) ganhou densidade e legitimidade no século XX, porém a utilização de técnicas métricas remonta ao século XIX. Em 1869, por suas experiências, Galton tentou identificar cientistas que utilizassem critérios como a menção dos nomes em bibliografias. Na sequência, valendo-se de métodos estatísticos, Campell, em 1896, analisou a dispersão de assuntos em publicações (ALVARAD0, 2007).

Paul Otlet - considerado por historiadores franceses o criador da bibliometria - definiu a bibliometria como a área que se ocupa da medida ou da quantidade aplicada a livros (ARAÚJ0, 2006). Já os autores de origem anglo-saxônica atribuem a criação do termo a Pritchard, que propôs sua utilização em substituição à bibliografia estatística. A bibliometria foi caracterizada por Pritchard (1969) como o conjunto de métodos e técnicas quantitativos para a gestão de bibliotecas e instituições envolvidas com o tratamento de informação (SANTOS; KOBASHI, 2009).

A ferramenta é um conjunto de leis e princípios empíricos que contribuem para estabelecer os fundamentos teóricos da Ciência da Informação (BORSCHIVER; GUEDES, 2005). Seu princípio é o de analisar a atividade científica ou técnica por meio de estudos quantitativos das publicações. Configura-se como uma área da Ciência da informação, que analisa a produção científica registrada (ROSTIROLLA, 2014).

Em termos genéricos, Vanti (2002) definiu algumas possibilidades de aplicação das técnicas bibliométricas, cienciométricas e infométricas: reconhecer as tendências e o crescimento do conhecimento em uma área; identificar as revistas do núcleo de uma disciplina; mensurar a cobertura das revistas secundárias; distinguir os usuários de uma disciplina; prever as tendências de publicação; estudar a dispersão e a obsolescência da literatura científica; prever a produtividade de autores individuais, organizações e países; medir o grau e os padrões de colaboração entre autores; analisar os processos de citação e cocitação; determinar o desempenho dos sistemas de recuperação da informação; avaliar os aspectos estatísticos da linguagem, das palavras e das frases; examinar a circulação e o uso de documentos em um centro de documentação; e medir o crescimento de determinadas áreas e o surgimento de novos temas.

0 estudo bibliométrico pode ser utilizado para diversos fins, por exemplo, para avaliar a produtividade e a qualidade da pesquisa dos cientistas por meio da medição com base nos números de publicações e citações dos diversos pesquisadores, o que pode revelar os avanços e as tendências de publicações nas diversas áreas do conhecimento. Além disso, para acompanhar os estudos desenvolvidos nas diferentes esferas do conhecimento científico, verificando os autores que mais publicam, os periódicos que publicam em uma determinada área, entre outros (SILVA; SANTOS; RODRIGUES, 2011).

Scopus é uma base de dados multidisciplinar e uma importante fonte para bibliotecários, cientistas da informação, editores e pesquisadores que desejam recuperar 
e avaliar a literatura científica. Foi produzida pela editora Elsevier em novembro de 2004 com cobertura desde 1960. Contém resumos de 69 milhões de itens, mais de 5.000 editoras internacionais, incluindo a cobertura de 16.500 revistas, referências e índices das literaturas científica, técnica e médica (ABU-RUMMAN, 2017).

A base Scopus cobre as seguintes áreas do conhecimento: química, física, matemática, engenharia, ciências da saúde e vida, ciências sociais, psicologia, economia, biologia, agricultura, ciências ambientais e ciências gerais. Mais de $60 \%$ dos títulos são de outros países que não os Estados Unidos, e 85\% do conteúdo é indexado utilizando os vocabulários controlados para a definição das palavras-chave e/ou descritores (MESQUITA et al., 2006).

A interface permite a pesquisa por assunto, autor, palavras do texto, ano etc., e os resultados podem mostrar documentos sobre os temas pesquisados e/ou as citações recebidas por esses documentos. A pesquisa básica pode ser feita por assunto, com delimitação de campos de dados, anos de publicação e áreas do conhecimento. A pesquisa avançada permite 0 uso de estratégias complexas, utilizando operadores booleanos e códigos dos campos de dados (SILVA; TOLEDO FILHO; PINTO, 2009). A base Scopus encontra-se juntamente com 0 Google Scholar e a Web of Science entre as maiores bases de dados multidisciplinares.

\section{Metodologia}

A coleta de dados foi realizada a partir de informações na base de busca de artigos científicos Scopus, disponível no Portal de Periódicos Capes. A pesquisa ocorreu no dia 18 de abril de 2019, utilizando os termos "políticas públicas", "esporte" e "lazer" em inglês (public policy), (sport) e (leisure) e foi feita a partir da expressão booleana: (TITLE-ABS-KEY (public policy)) AND (TITLE-ABSKEY (sport)) ou (TITLE-ABS-KEY (public policy)) AND (TITLE-ABS-KEY (leisure)). Buscaram-se os artigos que contivessem estes termos no título, resumo ou palavras-chave. A pesquisa limitou-se também a periódicos no Brasil e no mundo.

Conseguiram-se informações relacionadas à quantidade de artigos por ano, autor, área, instituição, país e periódico. Quanto à análise temporal, foram obtidas equações de regressão exponencial do número de artigos $(Y)$ em função do ano $(X)$, restringindo a análise ao período de 2008 a 2017. 0 período analisado não incluiu 0 ano de 2018, tendo em vista que a coleta dos dados foi realizada em abril de 2019, e a quantidade de publicações deste ano provavelmente poderia estar subestimada pelo fato de todas as informações de publicações não terem sido lançadas, seja por possíveis atrasos no cadastro das publicações na base Scopus (2018). Assim, com base nestas equações de regressão, foram calculadas as taxas médias de crescimento anual das publicações.

\section{Análise e discussão dos resulta- dos}

0 Gráfico 1 apresenta os países que mais publicaram no mundo a respeito do tema Política pública de esporte e lazer na base Scopus.

\section{A QUALIDADE DE ENSINO QUE VOCE JÁ GONHECE.}

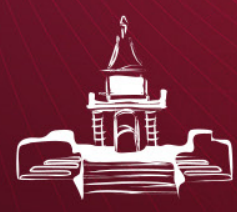

UNIVERSIDADE

CANDIDO

MENDES

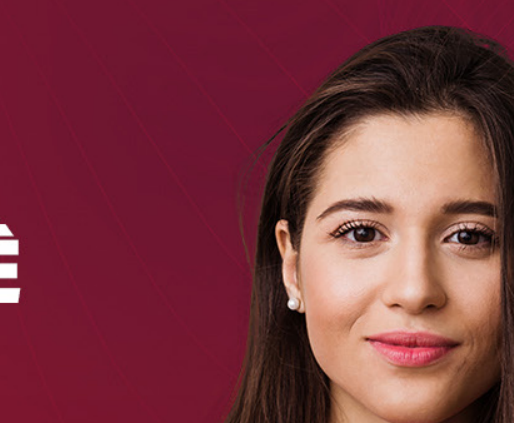

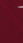

-

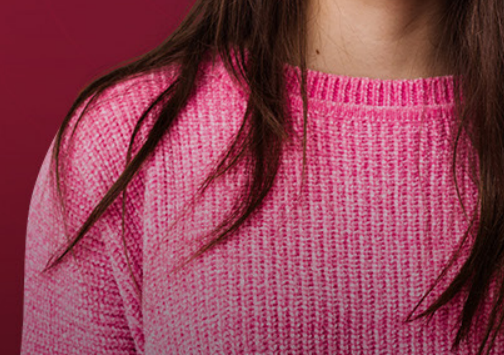


Gráfico 1 - Países com mais publicações no mundo sobre todos os temas e sobre o tema "Políticas públicas de esporte e lazer" na base Scopus.

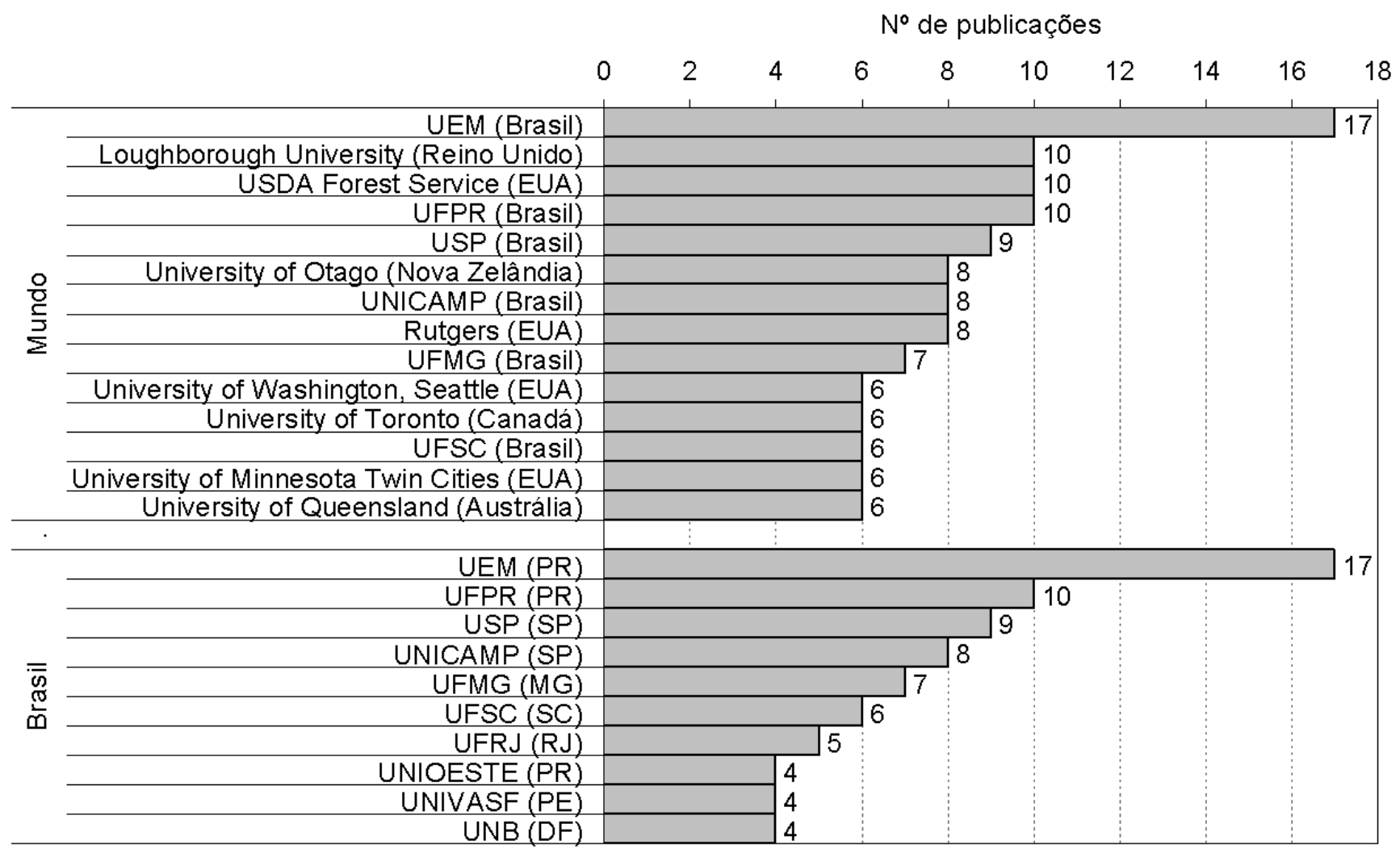

Observando-se o Gráfico 1, nota-se que Estados Unidos é o país que mais publica na base Scopus tanto em termos gerais como no tema estudado - Política pública de esporte e lazer. Os valores encontrados também estão muitos próximos, havendo um aumento no percentual de produção quando a busca é pelo tema estudado (28,8\%) contra $(27,3 \%)$ de todas as publicações. A China é o segundo país que mais publica no mundo, independentemente do tema, e o Brasil, o $15^{\circ}$ colocado. Quando se analisa o tema estudado, há uma inversão na segunda posição, onde o Brasil ocupa este lugar com 12,6\% da produção, e a China cai para o $10^{\circ}$ lugar empatando com a Alemanha, com 1,7\% das publicações sobre 0 tema. Isso demonstra a representatividade que o Brasil ocupa quanto ao tema estudado - Política pública de esporte e lazer.

No Gráfico 2, são apresentadas as quantidades de publicações sobre todos os temas ou sobre o tema no mundo e no Brasil.

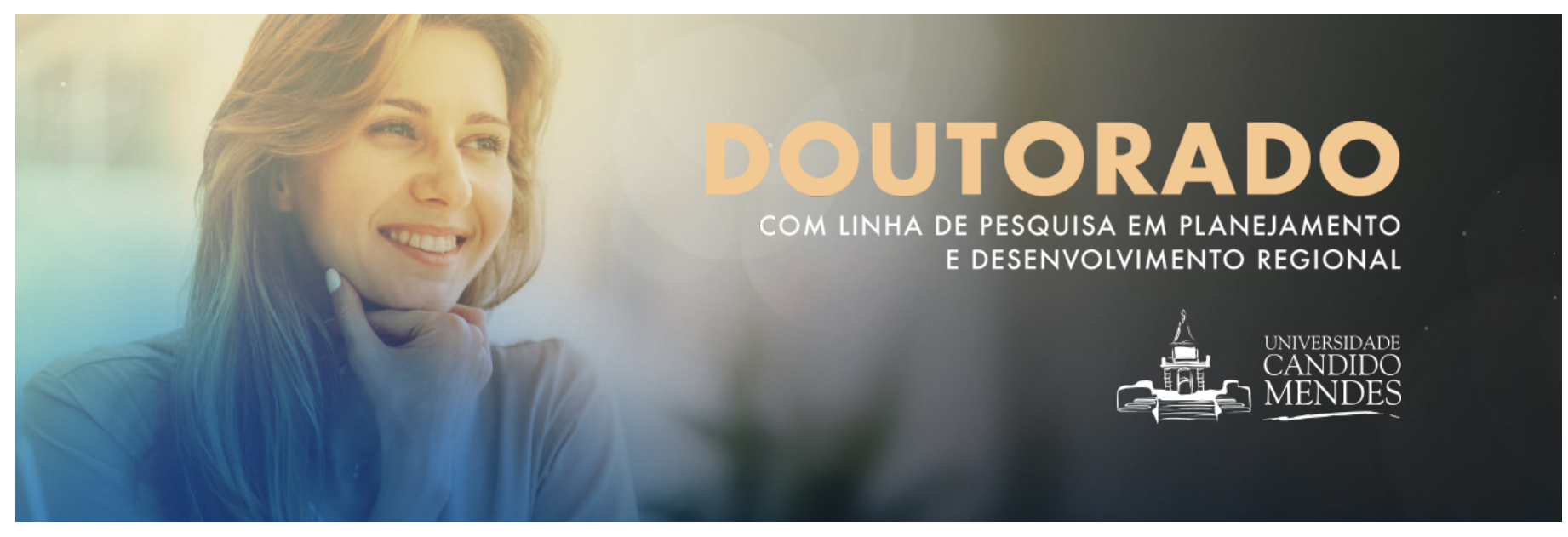


Gráfico 2 - Número de publicações na base Scopus por ano (2008 a 2017) considerando: (A) todos os autores e todos os temas no mundo; (B) os autores do Brasil e todos os temas; (C) todos os autores e o tema no mundo "Políticas públicas de esporte e lazer" e; (D) os autores do Brasil e o tema "Políticas públicas de esporte e lazer".

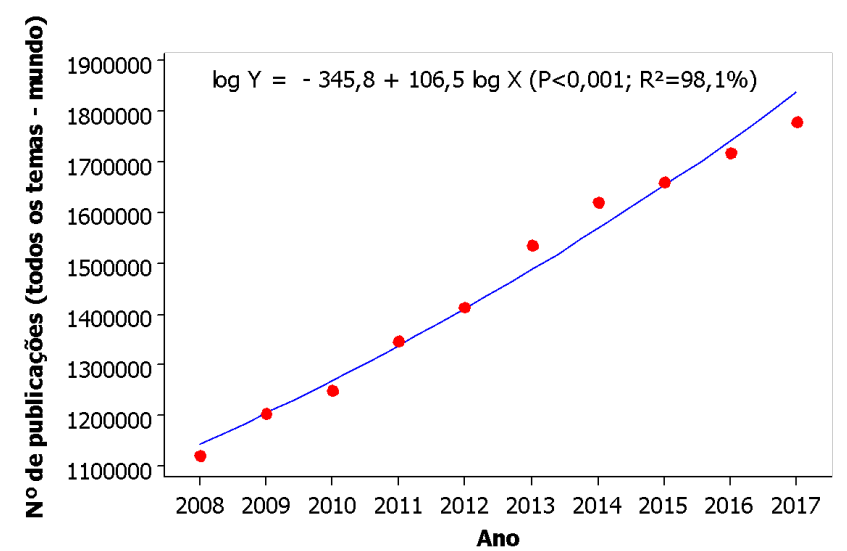

(A)

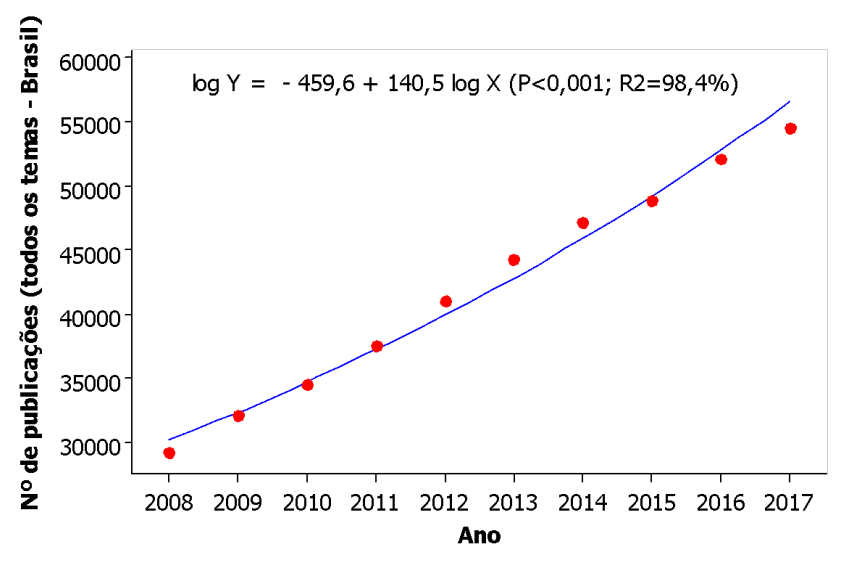

(B)

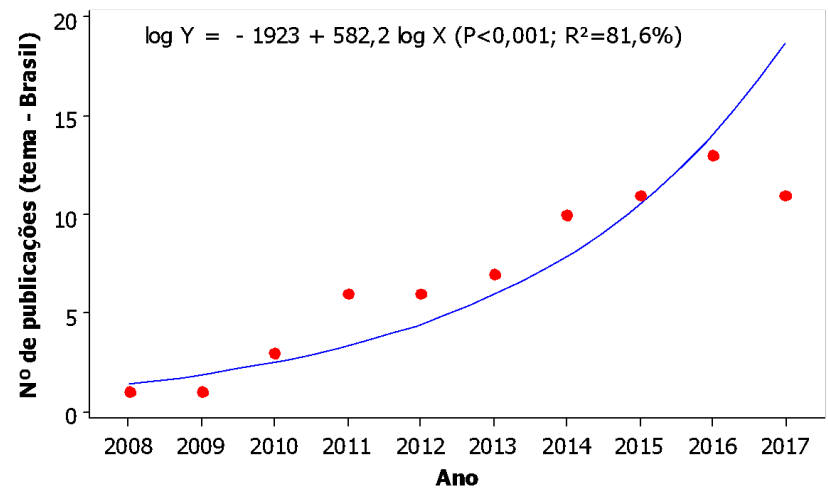

(D)

\section{DOUTORADO \\ COM LINHA DE PESQUISA EM INSTRUMENTOS \\ DE POLÍTICAS PÚBLICAS}


Observa-se, no Gráfico 2, que todas as equações foram significativas $(P<0,01)$ e, portanto, válidas estatisticamente para explicar a evolução temporal do número de publicações na década compreendida entre 2008 e 2017.
Com base nas equações de regressão exponencial apresentadas no Gráfico 2, foram calculadas as taxas médias de crescimento anual das publicações, cujos valores são apresentados no Gráfico 3.

Gráfico 3 - Taxa média de crescimento anual das publicações mundial e de brasileiros considerando todos os temas e o tema "Políticas públicas de esporte e lazer".

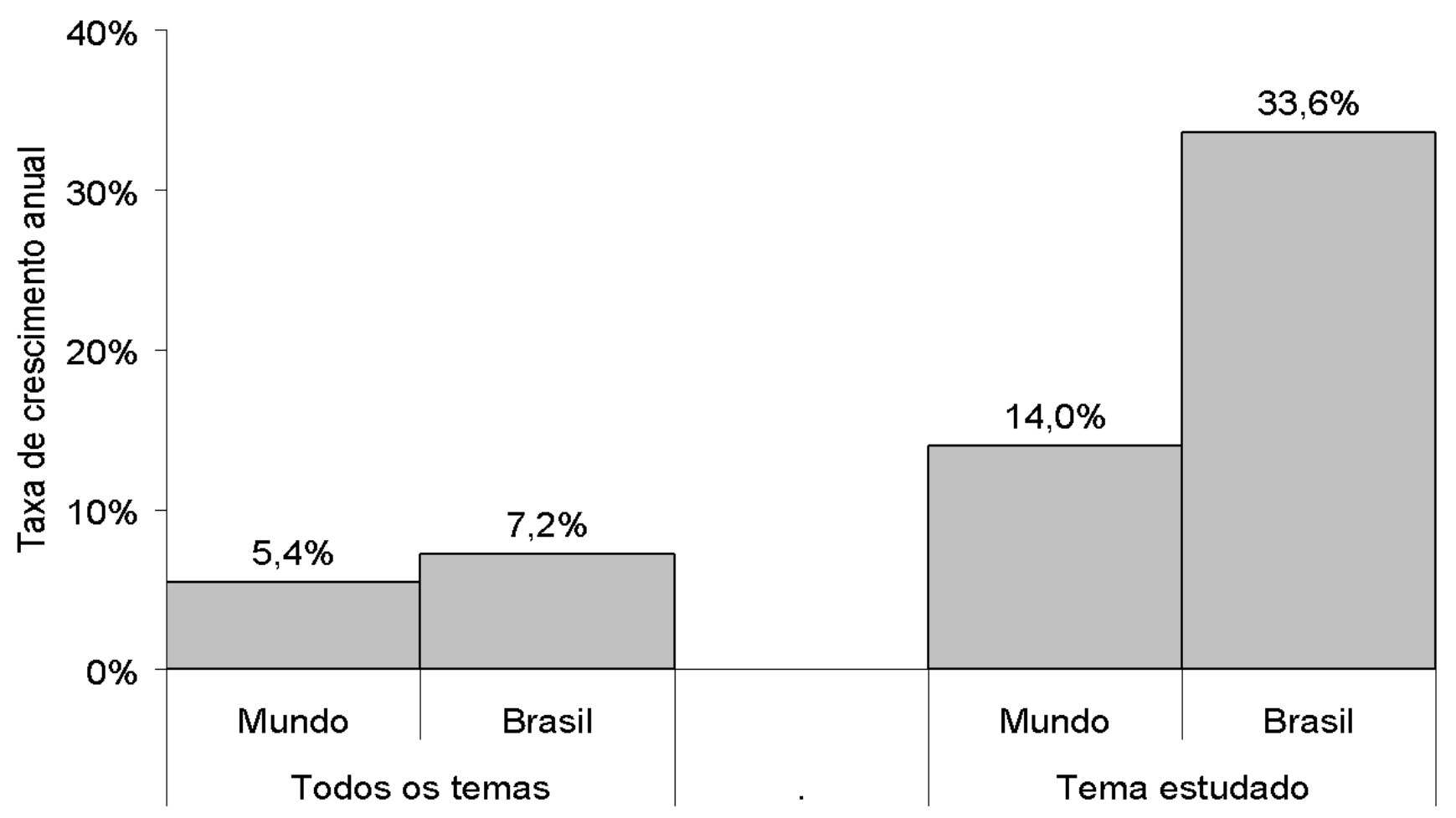

No Gráfico 3, percebe-se que, mundialmente, o número de publicações sobre todos os temas cresceu $5,4 \%$ e, no Brasil, esse número foi de 7,2\%. Quando se avalia 0 tema estudado no mundo, Política pública de esporte e lazer apresentou, em média, 14\% de crescimento ao ano, quase 0 triplo do valor sobre todos os temas publicados. A grande diferença foi quando se analisou o tema Política pública de esporte e lazer no Brasil, apresentando um crescimento exponencial, atingindo 33,6\%, mais de 4 vezes o número de publicações no Brasil sobre todos os temas.

No Gráfico 4, podem-se observar as instituições que mais publicam a respeito de política pública de esporte e lazer no mundo e no Brasil. 
Gráfıco 4 - Instituições que mais publicam, mundialmente e no Brasil, a respeito do tema Políticas públicas de esporte e lazer.

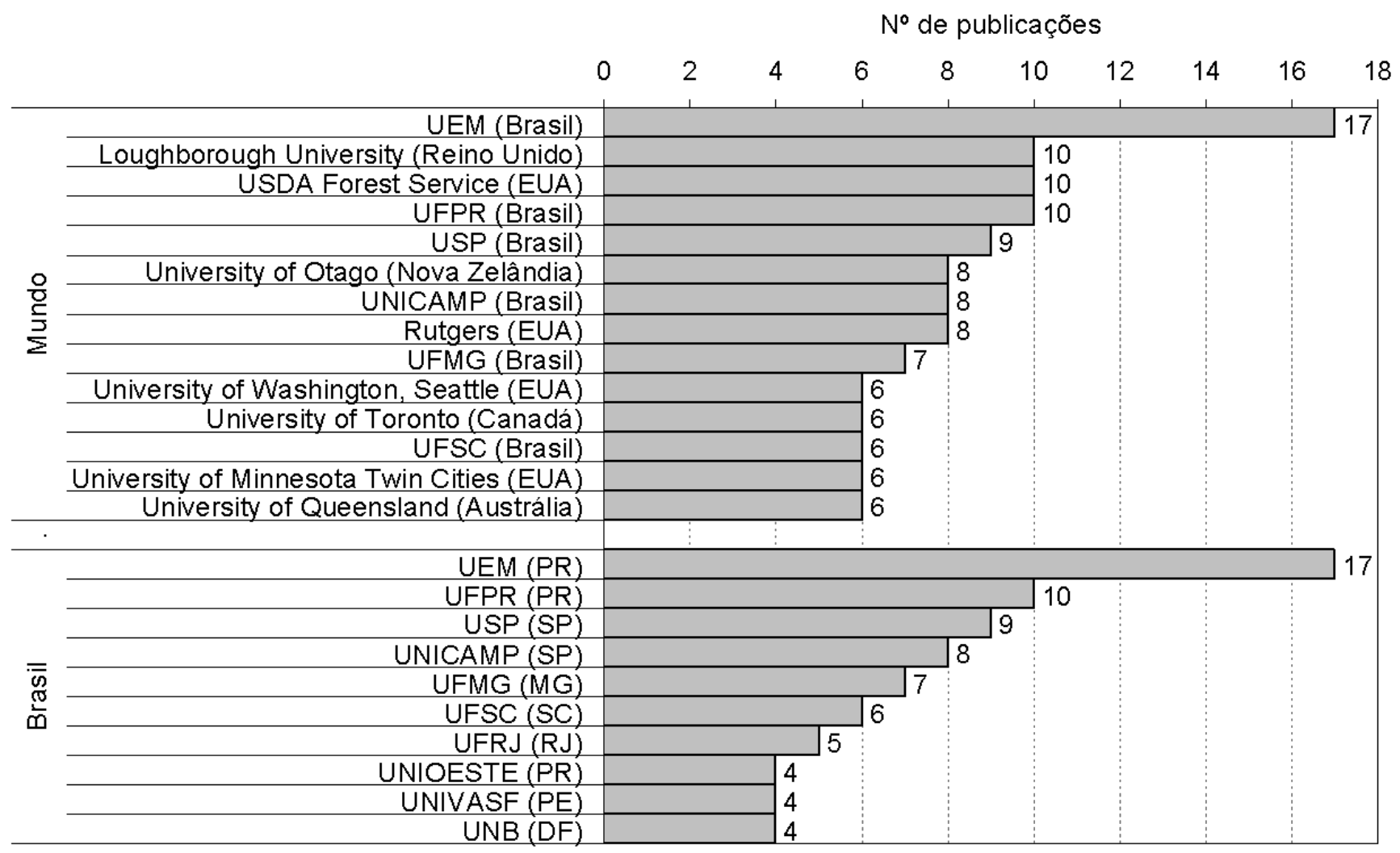

Abreviações (instituições nacionais): UEM - Universidade Estadual de Maringá; UFPR Universidade Federal do Paraná; USP - Universidade de São Paulo (Brasil); UNICAMP - Universidade

Estadual de Campinas; UFMG - Universidade Federal de Minas Gerais; UFSC - Universidade

Federal de Santa Catarina; UFRJ - Universidade Federal do rio de Janeiro; UNIOESTE -

Universidade Estadual do Oeste do Paraná; UNIVASF - Universidade Federal do Vale do São

Francisco e UNB - Universidade de Brasília.

Um dado relevante pode ser constatado no Gráfıco 4, demonstrando que a instituição que mais publica no mundo sobre o tema Política pública de esporte e lazer é a brasileira Universidade Estadual de Maringá (UEM), seguida das instituições Loughborough University (Reino Unido); USDA Forest Service (UEA) e Universidade Federal do Paraná (UFPR) (Brasil), todas classificadas em segundo lugar. Ocorreu também uma predominância de instituições brasileiras entre as instituições com mais publicações sobre o tema, totalizando 6 das 14 que mais publicam, seguidas por 4 instituições americanas. Qual o motivo de temos 14 instituições e não 10 ? 0 fato é que 5 instituições ficaram empatadas em $10^{\circ}$ lugar, com 6 publicações cada. No Brasil, o resultado não é diferente, a UEM é a universidade com mais publicações, seguida da UFPR, em $2^{\circ}$ Lugar; a Universidade de São Paulo (USP), em 30; e a Universidade Estadual de Campinas (Unicamp), em $4^{0}$ lugar.

No Gráfıco 5, são apresentados os autores no mundo e no Brasil com maiores quantidades de publicações sobre o tema política pública de esporte e lazer. 
Gráfıco 5 - Autores com maiores quantidades de publicações sobre o tema "Polític pública de esporte e lazer" na base Scopus.

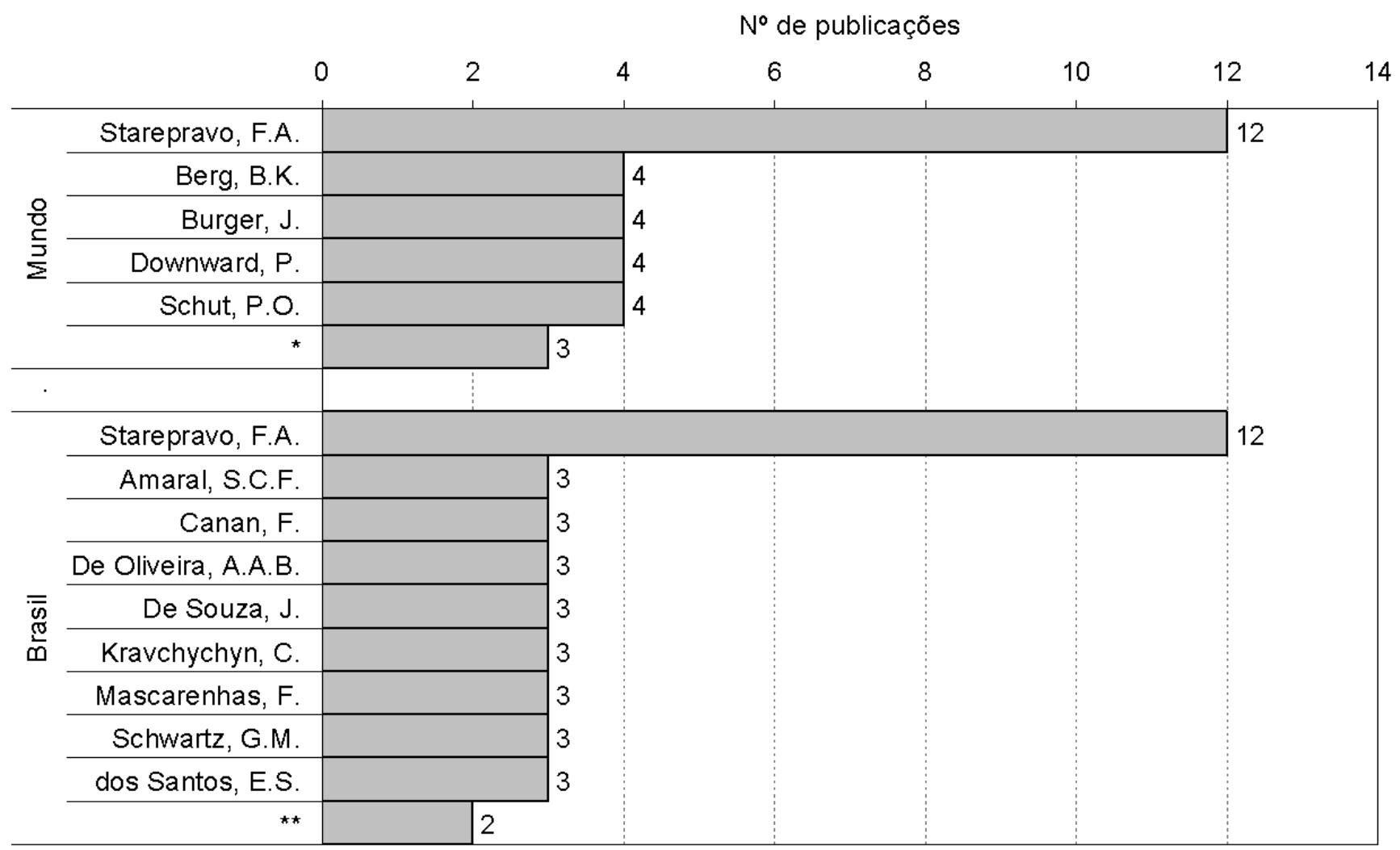

* 3 artigos: Amaral, S.C.F.; Canan, F.; Charrier, D.; De Oliveira, A.A.B.; De Souza, J.; Kellison, T.B.; Kravchychyn, C.; Mascarenhas, F.; Piggin, J.; Rasciute, S.; Ratten, V.; Schwartz, G.M.; Stenling, C.; dos Santos, E.S. ** 2 artigos: Barbosa-Rinaldi, I.P.; Galatti, L.R.; Malta, D.C.; Marchi Júnior, W.; Marchi, W.; Paes, R.R.; Reis, A.C.; Tavares, G.H.; Vieira, M.C.; Werle, V.; de Oliveira, A.A.B.

O levantamento de informações sobre a produção científica em políticas públicas de esporte e lazer no Brasil tem sido o foco de vários pesquisadores no País, onde autores brasileiros se destacam internacionalmente.

Ao analisarmos o Gráfico 5, vimos que o Brasil se destaca, pois é possível identificar que o autor que mais publica na base Scopus no mundo sobre o tema Política pública de esporte e lazer é um brasileiro: Starepravo, F. A., com um total de 12 publicações, seguido de Berg, B.K.; Burger, J.; Downward, P. e Schut, P.O., todos em segundo lugar, com 4 publicações. No Brasil, este mesmo autor também lidera o ranking com 12 publicações, seguido, em segundo lugar, por Amaral, S.C.F.; Canan, F.; Charrier, D.; De Oliveira, A.A.B.; De Souza, J.; Kellison, T.B.; Kravchychyn, C.; Mascarenhas, F.; Piggin, J.; Rasciute, S.; Ratten, V.; Schwartz, G.M.; Stenling, C.; dos Santos, E.S., todos com 3 publicações.

É possível observar, no Gráfico 6, as principais áreas em que os artigos relacionados ao tema Política pública de esporte e lazer estão vinculados. 
Gráfıco 6 - Principais áreas de vinculação dos artigos publicados na base Scopus e relacionados ao tema "Política pública de esporte e lazer"

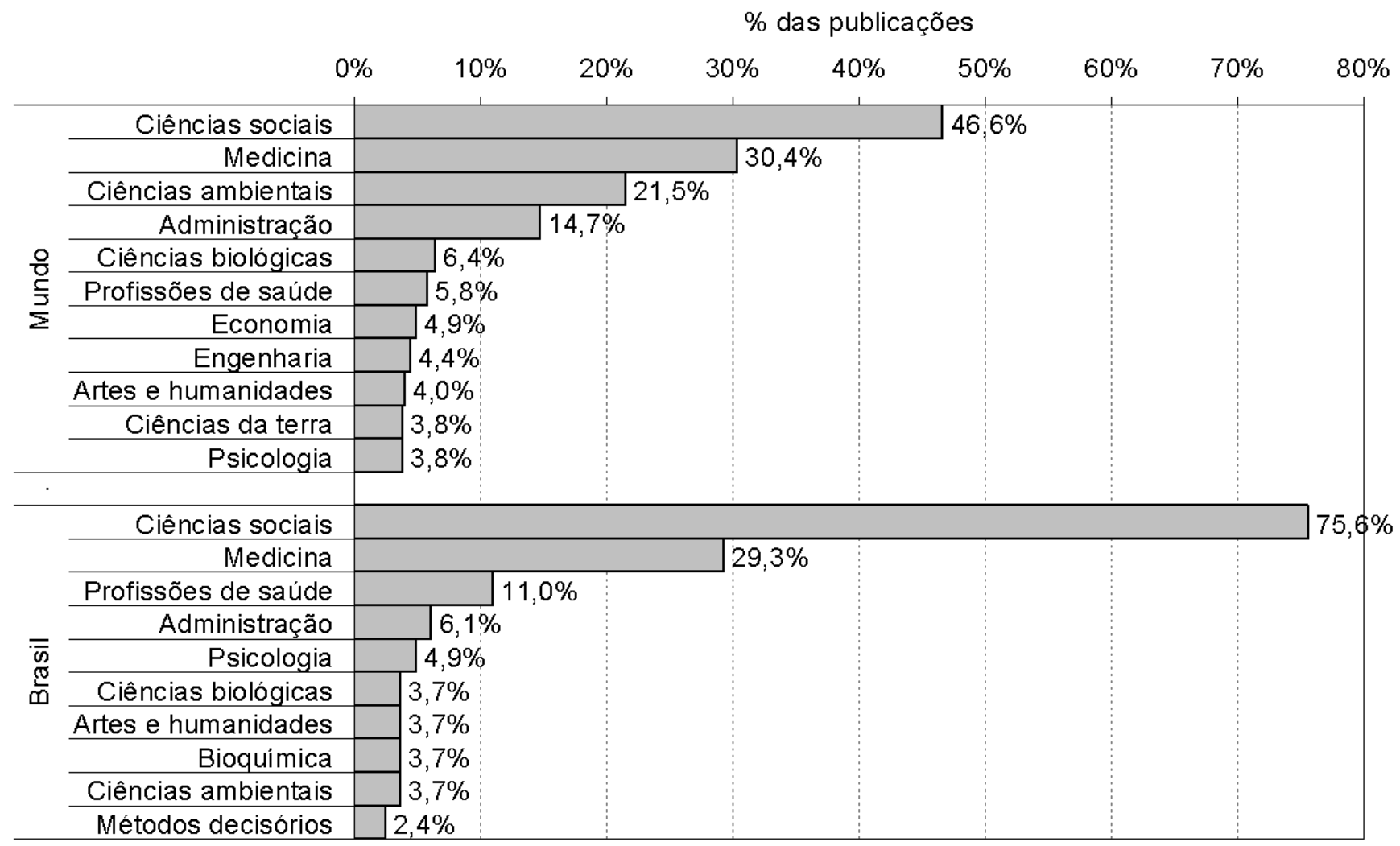

Quando relacionamos as áreas de conhecimento ao tema Política pública de esporte e lazer, observamos que se destacam as áreas de ciências sociais, medicina e ciências ambientais, quando analisamos as publicações no mundo. No Brasil, segue a mesma ordem para o $1^{\circ}$ e o $2^{\circ}$ lugares, ficando em $3^{\circ}$ a área de profissões da saúde. 0 que chama a atenção nesta Figura 6 é que, ao compararmos as publicações da área de ciências sociais no mundo
(46,6\%) e no Brasil (75,6\%), a representatividade da área no Brasil é muito mais expressiva. Os valores encontrados na área de medicina no mundo $(30,4 \%)$ e no Brasil (29,3\%) estão muito próximos.

No Gráfıco 7, são apresentados os periódicos com maiores quantidades de publicações relacionados ao tema Política pública de esporte e lazer.

M E S T R A D 0

PESQUISA OPERACIONAL E INTELIGÊNCIA COMPUTACIONAL LINHA DE PESQUISA EM SAÚDE

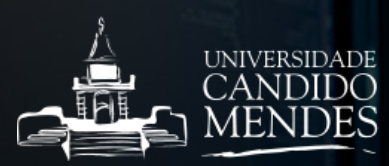




\section{Gráfıco 7 - Periódicos com mais publicações sobre o tema "Política pública de esporte e lazer".}

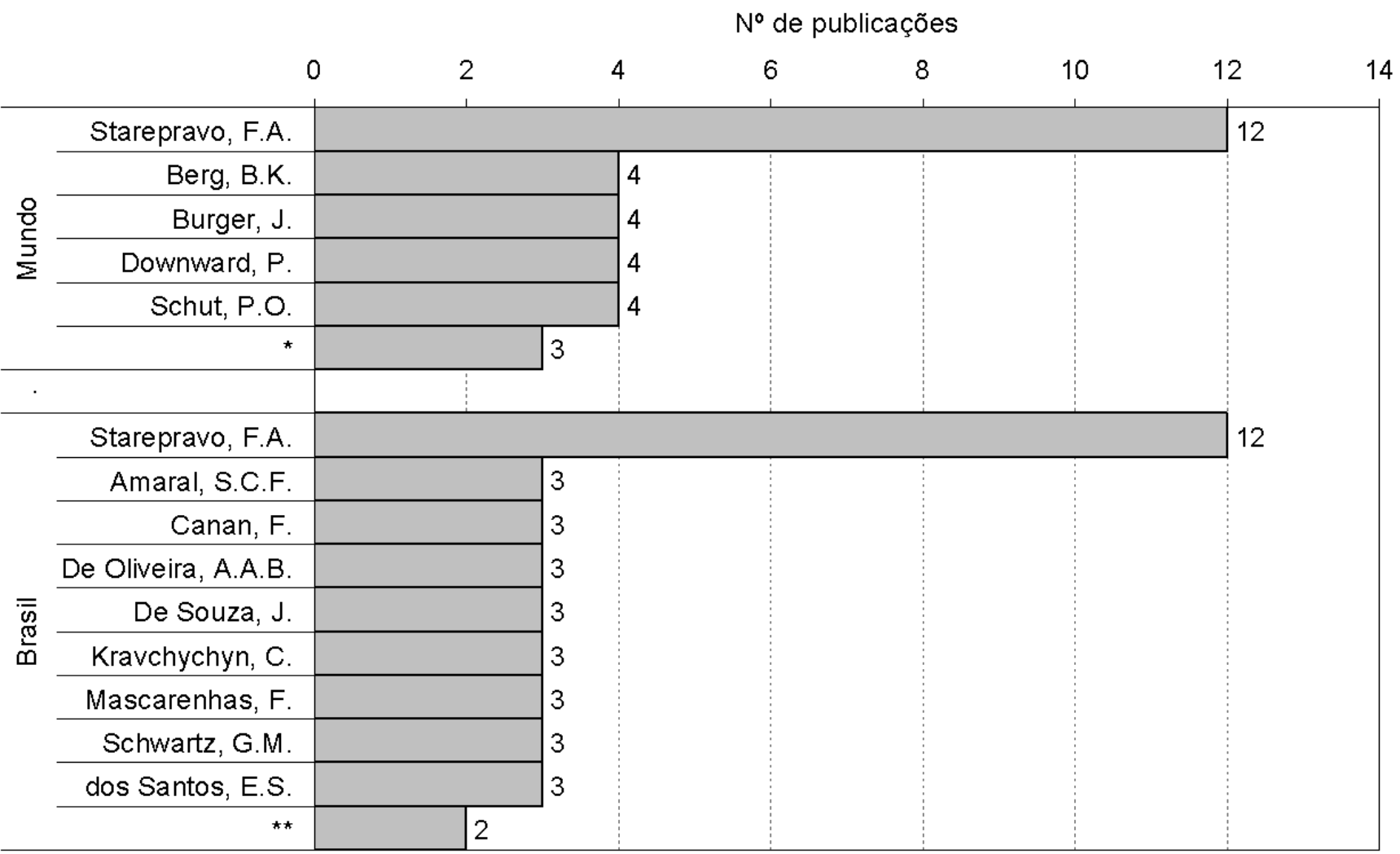

Abreviaturas: Int. rev. sociol. sport (International Review For The Sociology Of Sport); Rev. Bras. Ciênc. Esporte (Revista Brasileira De Ciencias Do Esporte); RBCE (Revista Brasileira De Ciencias Do Esporte); Rev. Bras. Cineantropom. Desempenho Hum. (Revista Brasileira De Cineantropometria E Desempenho Humano); J. Phys. Educ. (Journal Of Physical Education Maringa).

Ao analisarmos o Gráfico 7, constatamos que, em nível mundial, o periódico que aparece em primeiro lugar é brasileiro - Movimento, revista de educação física da Universidade Federal do Rio Grande do Sul (UFRGS), com 29 publicações, seguida pelo International Journal of Sport Policy, com 17 publicações e Environmental Management, com 13 publicações. Em relação às publicações no Brasil, o periódico Movimento também ficou em primeiro lugar, com 25 publicações, seguido pela Motriz - revista de educação física - e RBCE, ambas em segundo lugar, com 7 publicações cada. 0 fato de haver uma diferença dos quantitativos de publicações no periódico Movimento em relação à publicação mundial (29) e nacional (25) se deve a ocorrência de 4 publicações de autores estrangeiros neste periódico.

\section{Conclusão}

De acordo com os levantamentos efetuados foi possível verificar que no período de 2008 a 2017, que os Estados Unidos é o país que mais publica no mundo e o Brasil ocupa a $15^{\mathrm{a}}$ posição. Ao avaliar o tema estudado - políticas públicas de esporte e lazer -, o Brasil apresenta-se na $2^{\mathrm{a}}$ colocação.

0 número de publicações sobre o tema estudado no mundo cresceu $14 \%$ ao ano, enquanto no Brasil o aumento foi expressivo, totalizando $33,6 \%$.

Avaliando o número de publicações no mundo por instituição as quais os autores estão vinculados, nota-se que a instituição que mais publicou foi a UEM.

Entre os autores que mais publicam no mundo sobre 0 tema estudado aparece, em primeiro lugar, o brasileiro (Starepravo) com 12 publicações, 3 vezes mais que 0 segundo colocado, com 4 publicações.

Os dados coletados apresentaram uma tendência inter- 
disciplinar nas áreas de conhecimento no qual o tema estudado está vinculado. No mundo, a área de ciências sociais concentra $46,6 \%$ dos estudos, seguido da medicina $(30,4 \%)$ e ciências ambientais $(21,5 \%)$. No Brasil, estes resultados apresentaram-se de maneira similar com as ciências sociais, concentrando 75,6\% dos estudos, seguido da medicina (29,3\%) e profissões da área da saúde (11\%).
A título de análise, outro destaque encontrado foi que o periódico onde mais se publicam artigos sobre o tema Política pública de esporte e lazer no Brasil (Movimento: Revista de Educação Física da UFRGS) também é o primeiro em publicações no mundo, mostrando, assim, a relevância deste periódico para o Brasil e para 0 mundo.

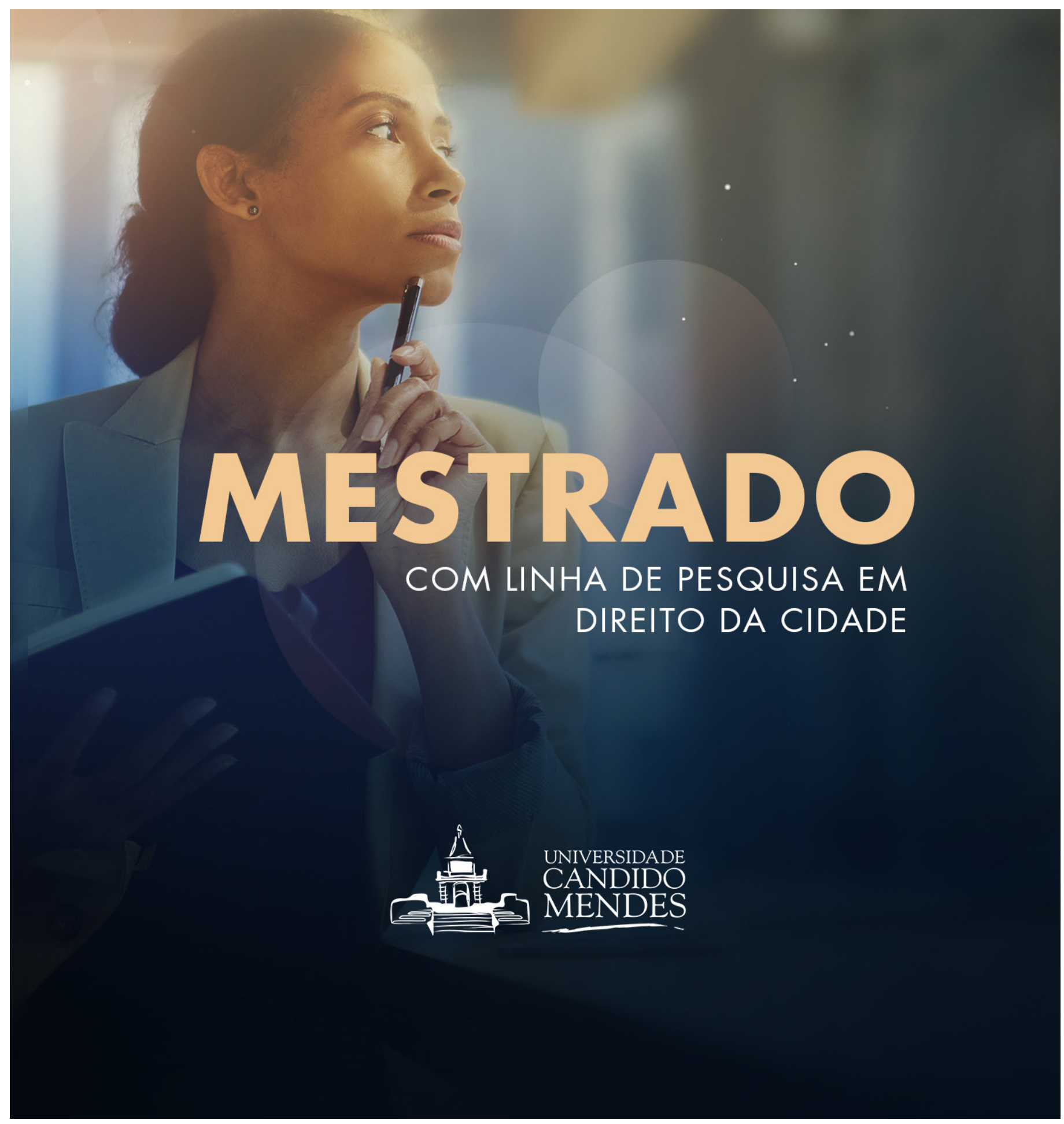




\section{Referências}

ALVARADO, R. U. A bibliometria, legitimação e estrutura. In: TOUTAIN, L.M.B.B. (org.). Para entender a ciência da informação. Salvador: EDUFBA, 2007. p.185-207.

ABU-RUMMAN, A. Scopus content coverage guide. Elsevier: [S.I.], August, 2017. Disponível em:

https://www.researchgate.net/publication/330161507_Scopus_Content_Coverage_Guide. Acesso em 02 de mai. 2019.

ARAÚJJO, C. A. Bibliometria: evolução histórica e questões atuais. Em questão, Porto Alegre, v. 12, n. 1, p. 11-32, jan./jun. 2006.

BENTO, J. O. Desporto: discurso e substância. Belo Horizonte: Campo das Letras, 2013.

BORSCHIVER, S.; GUEDES, V. L. S. Bibliometria: uma revisão da literatura dessa ferramenta estatística para a gestão da informação e do conhecimento, em sistemas de informação, de comunicação e de avaliação científica e tecnológica. In: SEMÍNÁRIO DE GESTIÓN TECNOLÓGICA ALTEC, 11., 2010, Salvador. Anais [...]

BRASIL. Constituição da República Federativa do Brasil de 1988. Brasília, 1988. Disponível em: http://www.planalto.gov.br/ccivil_03/constituicao/constituicao compilado.htm. Acesso em: 17 de abr. 2019.

CARON, A. E. G.; MARCHI JR., W.; SILVA, M. M. 0 mapeamento da produção científica sobre projetos esportivos no Brasil. Licere, Belo Horizonte, v. 21, n. 2, p. 26-49, jun. 2018.

LINHALES, M. A. A trajetória política do esporte no Brasil: interesses envolvidos, setores excluídos. 1996. 221f. Dissertação (Mestrado) - Faculdade de Filosofia e Ciências Humanas da Universidade Federal de Minas Gerais, Belo Horizonte, 1996.

MELO, M. A. Estado, governo e políticas públicas. In: MICELI, Sérgio. (org.). 0 que ler na ciência social brasileira (1970-1995). São Paulo: Anpocs, 1999. p. $59-100$.

MESQUITA, R.; et al. Elaboração e aplicação de instrumentos para avaliação da base de dados Scopus. Pesq. bras. Ci. Inf. Belo Horizonte, 2006. V. 11, p. $187-205$.

MORAES, P. M. et al. 0 Programa Segundo Tempo na região Centro-oeste: continuidade e estrutura burocrática do esporte nos municípios. R. bras. Ci. e Mov., Brasília, v. 25, n. 1, p. 129-140, 2017.

PRITCHARD, A. Statistical bibliography or bibliometrics? Journal of Documentation, v. 25, n. 4, p. 348-349, 1969.

REVERDITO, R. S. et al. O Programa Segundo Tempo (PST) em municípios brasileiros: indicadores de resultados no microssistema. J. Phys. Educ., Maringá. v. 27, n. 1, 2016.

ROSTIROLLA, G. Bibliometria como tema de tese: análise a partir da biblioteca digital de teses e dissertações. In: ENCONTRO BRASILEIRO DE BIBLIOMETRIA E CINETOPOMETRIA, 4., 2014, Recife. Anais eletrônico [...] Recife: UFPE, 2014. Disponível em: http://www.brapci.inf.br/article.php?dd0=0000014364\&dd90=0cedcf5be3. Acesso em: 01 mai. 2019.

SANTOS, R. N. M.; KOBASHI, N. Y. Bibliometria, cientometria, infometria: conceitos e aplicações. Pesq. bras. Ci. Inf, Brasília. v. 2, n. 1, p. 155-172, 2009.

SANTOS, E. S.; STAREPRAVO, F. A.; SOUZA NETO, M. S. Programa "Segundo Tempo", o vazio assistencial na região Nordeste. Movimento, Porto Alegre, v. 2, n. 21, p.759-771, jul. 2015. Trimestral. Disponível em: https://seer.ufrgs.br/Movimento. Acesso em: 02 mai. 2019.

SILVA, J.; TOLEDO FILHO, J. R.; PINTO, J. Análise bibliométrica dos artigos sobre controladoria publicados em periódicos dos programas de pós-graduação em Ciências Contábeis recomendados pela Capes. Revista ABCustos, São Leopoldo, v. 4, n. 1, p. 36-52, jan./abr. 2009.

SILVA, R. A.; SANTOS, R. N. M.; RODRIGUES, R. S. Estudo bibliométrico na base LISA: um enfoque nos artigos sobre os surdos. Em Questão, Porto Alegre, v. 27, p. 283-298, 2011.

STAREPRAVO, F. A. Políticas públicas para o esporte e lazer: conselhos municipais de esporte e lazer e outras formas de participação direta. In: CONGRESSO BRASILEIRO DE CIÊNCIAS DO ESPORTE, 15., 2007, Recife. Anais [...]. Disponível em: http://www.cbce.org.br/docs/cd/listaresumos.htm. Acesso em: 27 abr. 2019.

STAREPRAVO, F. A; MEZZADRI, F. M. Algumas contribuições de Pierre Bourdieu e Norbert Elias à discussão das políticas públicas para o esporte e lazer. In: SIMPÓSIO INTERNACIONAL PROCESSO CIVILIZADOR, 10., 2007, Campinas. Anais [...].Disponível em: http://www.uel.br/grupoestudo/processoscivilizadores/portugues/sitesanais/anais10/trabalhos_geral.htm\#F. Acesso em: 27 abr. 2019.

STAREPRAVO, F. A. et al. Eassim criou-se a Rede: aspectos técnicos, políticos e epistemológicos envolvidos na criação de desenvolvimento da Rede Cedes. Movimento, Porto Alegre, v. 20, n.1, p. 33-58, 2014.

STAREPRAVO, F. A. et al. Programa "esporte e lazer da cidade": onde o político/burocrático e o científico/ acadêmico se encontram? Movimento, Porto Alegre, v. 1, n. 23, p. 23-34, jan. 2018. Disponível em: https://seer.ufrgs.br/Movimento. Acesso em: 29 abr. 2019.

VANTI, N. A. P. Da Bibliometria à Webometria: uma exploração conceitual dos mecanismos utilizados para medir o registro da informação e a difusão do conhecimento. Ci. Inf., Brasília, DF, v. 31, n. 2, p. 152-162, 2002. 